\title{
De xawara, estratégias nativas e a pesquisa antropológica na Terra Indígena Yanomami
}

\author{
MARINA SOUSA \\ Universidade Estadual de Campinas, Campinas, São Paulo, Brasil \\ marina.antrorr@gmail.com
}

DOI 10.11606/issn.2316-9133.v29isuplp34-41

resumo $\mathrm{O}$ objetivo deste relato é descrever os principais impactos da pandemia do novo coronavírus na Terra Indígena Yanomami. A identificação de uma continuidade histórica de ação estatal para eliminação dos povos indígenas toma forma na omissão de atividades ilegais como garimpo, desmatamento e precário acesso à saúde. A partir destes fatores adversos, diversas estratégias nativas contra epidemias e contágio são elaboradas desde deslocamentos para a mata e distante de zonas de proximidade com a população nãoindígena. Essas estratégias visam o isolamento social em relação a áreas de maior contágio. Portanto, em frente a novo risco de genocídio aponta-se a necessidade da continuidade da atuação antropológica ainda que na impossibilidade de ingresso nas Terras Indígenas.

palavras-chave Terra Indígena Yanomami. COVID-19. Pesquisa antropológica.

On xawara, native strategies and anthropological research in the Yanomami Indigenous Land

abstract The purpose of this report is to describe the main impacts of the new corona virus in the Yanomami Indigenous Land. Omission of illegal activities such as gold mining, deforestation, and precarious access to health are shaped in the identification of a historical continuity of State action to eliminate indigenous people. Based on these adverse factors, several native strategies against the epidemics and contagion are elaborated from displacements to the forest and far from areas close to the non-indigenous population. These strategies aim the social isolation from areas of greater contagion. Therefore, in the face of a new risk of genocide, the need to continue anthropological actions, despite the impossibility of field research in indigenous lands.

keywords Yanomami indigenous land. COVID-19. Anthropological research 


\section{Xawara, estratégias nativas y la investigación antropológica en la Tierra Indígena Yanomami \\ resumen El propósito de este informe es describir los principales impactos del} Covid-19 en la Tierra Indígena Yanomami. Se identifica la continuidad histórica de la acción estatal para eliminar a los pueblos indígenas por el hecho de la omisión hacia actividades ilegales como la minería, la deforestación y el acceso deficiente a la salud. Sobre la base de estos factores adversos, se elaboran varias estrategias autóctonas contra las epidemias y el contagio a partir de los desplazamientos al bosque y de las zonas de proximidad a la población no autóctona. Estas estrategias tienen como objetivo el aislamiento social de las zonas de mayor contagio. Por lo tanto, ante el nuevo riesgo de genocidio, se señala la necesidad de la continuidad de la acción antropológica, aunque sea imposible entrar en las Tierras Indígenas.

palabras clave Tierra Indígena Yanomami. COVID-19. Investigación antropológica.

\section{Introdução}

Qual o lugar da Antropologia diante o cenário da pandemia do novo coronavírus, Covid-19, e o risco de adoecimento em massa dos povos indígenas? É com esse questionamento que iniciamos esse relato que tem como principal objetivo discutir os impactos imediatos da pandemia causada pelo vírus Covid-19 na Terra Indígena Yanomami (TIY) e sugere, sumamente, algumas possibilidades de atuação do(a) antropólogo(a) durante o período de isolamento social que pressupõe a não realização de pesquisa de campo.

A experiência de epidemias de doenças infecciosas não é novidade para os povos indígenas das Américas, sendo documentada em contextos que antecedem a propagação da Covid-19. ${ }^{1}$ Portanto, o presente relato pretende contribuir com um panorama da situação dos indígenas moradores da TIY, tendo como fio condutor a experiência diante de novo risco de genocídio, identificando continuidade histórica a partir de uma ação estatal coordenada para eliminação dos sujeitos indígenas, bem como as estratégias nativas contra epidemias e contágio. ${ }^{2} \mathrm{O}$ material é constituído de relatos de pesquisa de campo, notícias da pandemia entre povos indígenas de diversas mídias e a "Nota técnica para contribuir ao

\footnotetext{
${ }^{1}$ Carlos Fausto (2001) descreve situações de intenso despovoamento ocorrido por uma epidemia de varíola no ano de 1621 no interflúvio Pacajá-Tocantins. Introduzida pelas frentes de conquista, causou imenso impacto demográfico, levando diversos povos indígenas a buscarem áreas mais distantes e longe dos grandes cursos d'água. Alcida Ramos (1990, 1993) retrata a letalidade branca (não-indígena) enquanto um conjunto de estratégias burocráticas e de monopólio da violência estatal que visam a tentativa de eliminação dos povos indígenas. Em suas palavras a omissão é a letalidade branca mais eficiente.

${ }^{2}$ A Terra Indígena Yanomami é habitada pelos povos Yanomami e Ye’kuana, possui uma área com cerca de 9,6 milhões de hectares, localizada na fronteira do Brasil com a Venezuela, perfaz porções do estado de Roraima e do Amazonas. A população total é de cerca de 26.785 pessoas (Siasi/Sesai/MS, 2018), distribuídas em mais de 300 aldeias que constituem um conjunto multicomunitário
} 
combate da Covid-19 na Terra Indígena Yanomami” de autoria de Alcida Ramos et al. (2020), mantendo-se em diálogo com a bibliografia especializada.

Fatores adversos e ilegalidades que acometem os habitantes da TIY complicam as tentativas de enfretamento da pandemia e do contágio. ${ }^{3} \mathrm{O}$ direito originário ao território, garantido pelo artigo 231 da Constituição Federal de 1988, determina a demarcação a partir do uso, costume e tradição dos povos indígenas. ${ }^{4}$ Ora, a exploração intensiva de minerais, bem como a poluição de rios por mercúrio nunca constituiu prática cultural dos povos Yanomami e Ye'kwana. Atividade exógena, é caracterizada pela invasão de seu território por cerca de 20.000 garimpeiros que mantém formas ilegais de exploração aurífera. ${ }^{5} \mathrm{O}$ desmatamento é outro fator que precisa ser apontado. O crescimento de áreas invadidas e desmatadas, de acordo com um estudo do Instituto Homem e Meio Ambiente da Amazônia (Imazon), aponta a TIY como uma das áreas que mais sofre com atividades ilegais de desmatamento (cf. FONSECA et al, 2019). Por fim, a adequação do atendimento à saúde na TIY, previsto em lei, enfrenta inúmeras adversidades como falta de profissionais, equipamentos, estrutura física adequada, como também a ausência de antropólogos (as) nos Distritos Sanitários Especiais Indígenas (DSEI). ${ }^{6}$

Com um sistema de atendimento sanitário deficiente, invasões territoriais de pessoas que praticam desmatamento ilegal e exploração aurífera na região, a TIY - maior terra indígena do Brasil - com aldeias interligadas por diversas modalidades de vínculos como trocas, parentesco, festas, cerimônias mortuárias, enfrenta um desafio compatível com seu tamanho. Experiências com epidemias anteriores, continuidade histórica de negligência da ação estatal e estratégias nativas de enfrentamento, configuram elementos da experiência da pandemia no contexto contemporâneo indígena. A partir disto, quando estes grupos são apontados como vulneráveis, de que modalidade de vulnerabilidade estamos falando?

\footnotetext{
${ }^{3}$ A Rede Pró-Yanomami e Ye'kuana foi criada com o objetivo de divulgar informações e análises qualificadas frente ao avanço da Covid-19 na Terra Indígena Yanomami (AM/RR). A rede é constituída por antropólogos (as), linguistas, indigenistas, profissionais de saúde, jornalistas e advogados (as).

${ }^{4}$ Após um longo processo de reivindicações, denúncias e apoio de diferentes entidades nacionais e estrangeiras, cientistas e pesquisadores, a Terra Indígena Yanomami é demarcada via homologação do Decreto de 25 de maio de 1992. É importante ressaltar a participação de antropólogos neste processo com a elaboração de relatos e boletins científicos.

${ }^{5}$ Atividade garimpeira ilegal de mais de 20 mil garimpeiros na Terra Indígena Yanomami é denunciada por lideranças Yanomami e Ye'kwana, veja: https://www.socioambiental.org/pt-br/noticiassocioambientais/pandemia-da-covid-19-torna-urgente-expulsao-de-garimpeiros-da-terra-indigenayanomami. Acesso em 15/06/2020.

${ }^{6}$ Em nota publicada pela Associação Brasileira de Antropologia (ABA), a "reestruturação" dos cargos dos DSEI que previa a exclusão das categorias de Antropólogo e Pedagogo é duramente criticada, apontando o não cumprimento de determinações jurídicas. Disponível em: http://www.aba.abant.org.br/files/20200504_5eb0519d148b2.pdf. Acesso em: 17/06/2020
} 


\section{Continuidade mórbida e estratégias de enfrentamento}

A pandemia provocada pela propagação da COVID-19 e falência de diversos sistemas de saúde configuram uma crise sanitária em escala planetária. Em artigo de opinião publicado na Folha de São Paulo, intitulado "Agora somos todos índios", o antropólogo Bruce Albert (2020) aponta as fragilidades epidemiológicas frente a um vírus para o qual nenhuma pessoa possui anticorpos. O cenário de incertezas e risco de morte iminente acompanhou as diversas epidemias vivenciadas pelos povos indígenas na história recente. Xawara, palavra yanomami que designa uma modalidade de letalidade napëpë, ou seja, "brancos", não-indígenas está sendo utilizada para descrever a atual situação. ${ }^{7}$ Esta letalidade que aparece na forma de agressão direta ao corpo que se encontra doente por enfermidades exógenas, designava, historicamente falando, a infecção provocada pela malária, sarampo e outras síndromes gripais. O alargamento conceitual de Xawara, na interpretação Yanomami a respeito de epidemias, tem designado, igualmente, o poder destrutivo da COVID-19, uma vez que ambas enfermidades compartilham um universo sintomático e ontológico em comum.

A primeira notícia da chegada do novo coronavírus na Terra Indígena Yanomami vem da informação do óbito do primeiro jovem Yanomami, de apenas 15 anos de idade, no dia 09/04/2020. De acordo com informes da Secretaria Especial de Saúde Indígena-Sesai, esta foi a primeira morte notificada entre os povos indígenas. Às margens do rio Uraricoera, no estado de Roraima, localiza-se a aldeia Helepe, morada desse jovem. Negligência médica, incerteza de diagnóstico e risco de contaminação no próprio Hospital Geral de Roraima marcaram diversas idas e vindas do jovem à cidade de Boa Vista, culminando com o agravamento de seu quadro de saúde. O desfecho deste primeiro caso foi a síntese da sequência de desprezo pela vida indígena e suas cosmologias, pois ele foi enterrado carecendo o consentimento da família e desrespeitando rituais funerários. ${ }^{8}$

O primeiro foco da doença entre os Yanomami foi um alerta para que autoridades do poder público e do atendimento da saúde indígena ficassem atentas para situações potencialmente problemáticas quando da possível propagação do vírus. A TIY é

\footnotetext{
${ }^{7}$ Categorias e expressões êmicas são grafadas em itálico no corpo do texto

${ }^{8}$ O caso foi noticiado pelas repórteres Kátia Brasil e Emily Costa em abril de 2020. A impossibilidade de realização de rituais funerários dos Yanomami, durante o período da pandemia, aponta para dois fatores. $\mathrm{O}$ primeiro são as características inerentes ao ritual descritas por Bruce Albert (1985). O sistema ritual funerário yanomami envolve luto coletivo e mobiliza interações de afinidade entre aldeias de parentes e amigos, perpassando todo o conjunto multicomunitário. O ritual tem início a partir do luto coletivo, seguindo a exposição do cadáver, incineração de ossos, caçada realizada em coletivo e, por fim, a assembleia (reahu), momento de ingestão das cinzas do morto. O segundo fator é a impossibilidade da realização desses rituais durante a pandemia, uma vez que aumentaria o risco de contágio entre as pessoas, o que sugere a realização de sepultamento biosseguro. Todavia, essa modalidade de sepultamento não respeita o direito à consulta que os Yanomami possuem, tampouco promove alternativas para a realização do ritual num momento pós-pandemia. A não realização desses rituais tem efeitos diretos na socialidade dos Yanomami, uma vez que a realização do ritual mortuário implica a continuidade de uma boa vida dos vivos. Quando não realizado, os parentes vivos quedam-se tristes, raivosos e com saudade.
} 
continuamente visitada por missionários, profissionais de saúde, pesquisadores e militares que trabalham na região, o que configura a necessidade de controle e testagem dessas pessoas que podem estar assintomáticas e serem vetores da COVID-19. Há também intenso fluxo de indígenas que recorrem aos centros urbanos para atendimentos médicos, recebimento de auxílios governamentais, compra de medicamentos, produtos industrializados, comida e roupa.

O trânsito de pessoas é algo a ser discutido nos âmbitos estatais e deliberativos de medidas administrativas e proposição de políticas públicas a partir das lógicas indígenas de deslocamento, como também seus protocolos de consulta. ${ }^{9}$ Isto posto, é perceptível que o isolamento social, medida de maior eficácia na prevenção da propagação do vírus, desde a lógica de deslocamento nas terras indígenas, dá-se pelo isolamento social para com os nãoindígenas, uma vez que as lógicas de sociabilidade pressupõem convívio em família, visita a parentes distantes e compartilhamento de substâncias.

A continuidade histórica da vivência de epidemias e ausência de ação estatal para prevenção é presente na experiência Yanomami e configura novo risco de genocídio. Fatores adversos como garimpo, desmatamento e problemas na saúde indígena caracterizam situações de risco diante a propagação do novo coronavírus. A monitoração de possíveis casos e outras enfermidades pode ser realizada a partir da radiofonia, principal meio de comunicação das diversas aldeias da TIY, uma vez que a maioria delas são distantes de centros urbanos.

Assim sendo, estratégias nativas contra epidemias e contágio são elaboradas a partir do xamanismo e do wayumi, prática socioespacial que corresponde ao abandono temporário das aldeias em sentido a acampamentos familiares de caráter temporário na floresta, distante de postos de saúde, missões ou batalhões de fronteira. No cenário da pandemia, esta estratégia corresponde ao desejo de distanciamento dos não-indígenas a fim de evitar o contágio, como também manutenção de atividades cotidianas de pesca, caça e agricultura. $\mathrm{O}$ bloqueio espiritual do território, bem como a prática da medicina tradicional são atividades do conhecimento xamânico que pretendem cuidar do planeta adoecido.

A obra "A queda do céu", de autoria de Davi Kopenawa e Bruce Albert (2015), pode ser entendida como uma "crítica xamânica da economia política da natureza", nas palavras de Bruce Albert (1992). A análise das práticas predatórias de produção e da relação com a natureza que os não-indígenas assumem aponta para a existência de um mundo adoecido pelas ações do povo da mercadoria. As práticas predatórias dos napëpë resultam numa forma radical de predação, onde o outro não é apenas consumido, mas sua possibilidade de existência é aniquilada. Neste cenário, a ação dos xamãs de "segurar o céu" pode ser

\footnotetext{
${ }^{9}$ A garantia da consulta é direito que deve ser percebido quando da tomada de decisões administrativas e legislativas que tenham impacto direto na vida das populações indígenas. No caso da TIY, existe o Protocolo de Consulta elaborado pelos Yanomami e Ye'kwana e o Plano de Gestão Territorial e Ambiental da TIY (2019), que apresenta diretrizes a respeito da assistência à saúde
} 
compreendida como uma espécie de bloqueio espiritual do território e cura de um planeta que arde adoecido.

$\mathrm{Na}$ história recente, os Yanomami sofreram com outras epidemias de doenças infecciosas. A abertura da Perimetral Norte na porção leste da TIY durante a década de 1970 marcou a chegada de grande número de não-indígenas, desmatamento e doenças. A estrada trouxe consigo, nos idos dos anos de 1980, elevado número de garimpeiros, momento no qual a TIY sofreu com a maior invasão de seu território, poluição de rios e exploração ilegal de ouro. Esta época foi cenário de invasão, doenças, exploração e mortes dos Yanomami causadas por epidemia de malária e outras doenças infecciosas. Portanto, os eventos que traçam a história do contato com a sociedade nacional são perpassados por alastramento de doenças, contágio, contaminação de rios e exploração.

Diante da COVID-19, percebemos que experiências indígenas com epidemias anteriores, bem como a continuidade histórica de omissão e violência estatal constituem uma específica modalidade de vulnerabilidade. Os povos indígenas continuamente elaboram estratégias socioespaciais, de conhecimento e cura xamânica para lidar com diversas situações políticas e sociais. É necessário, portanto, elaborar a crítica da classificação destes povos enquanto vulneráveis, uma vez que esta vulnerabilidade é imposta por agressões externas a lógica indígena. Ou seja, esta vulnerabilidade se dá por conta de omissão estatal e continuidade histórica de invasão de seus territórios, bem como dificuldades na saúde indígena.

Assim, como o processo demarcatório da TIY foi marcado por colaboração de toda uma geração de antropólogos, a pandemia sugere um campo específico de atuação antropológica. A criação de redes de apoio, produção de dados e monitoramento alternativo do avanço da doença constituem possíveis ações no campo da Antropologia. A partir disso, no que diz respeito à elaboração de planos de contenção do vírus a nível nacional na saúde indígena, é perceptível a carência do saber antropológico e do respeito aos protocolos e estratégias nativas. Diante da impossibilidade de realização de pesquisa de campo nas Terras Indígenas durante todo o período de isolamento social, a pesquisa antropológica no campo da etnologia indígena passa a ser exercida de maneira virtual com a perspectiva de atendar a demanda deste campo do conhecimento no momento da epidemia.

A necessidade da continuidade da atuação antropológica sugere que a produção de relatos, artigos e dossiês sobre a Covid-19, bem como a manutenção da comunicação e articulação junto a parceiros nativos da pesquisa são estratégias possíveis durante o período de isolamento social. A realização de seminários e conversas nas plataformas digitais com lideranças indígenas, antropólogos (as) e profissionais da saúde igualmente colaboram com a denúncia de situações de negligência e publicização das condições de enfrentamento ao novo corona vírus. Por fim, a possibilidade de organização de campanhas virtuais de arrecadação de alimentos, equipamentos e insumos também podem ser modos de atuação nesse cenário. 


\section{Uma nota final}

Este relato teve a intensão de colaborar com o entendimento processual da experiência indígena frente à propagação de novas epidemias. A continuidade histórica da ação estatal que seguidamente eliminou povos indígenas aparece na forma da omissão, precariedade de serviços e burocracia. A invasão de mais 20 mil garimpeiros na Terra Indígena Yanomami, o crescente desmatamento e as dificuldades de acesso a serviços de saúde, constituem fatores agravantes para o risco de possível genocídio. Por isso, os protocolos de consulta elaborados pelos Yanomami e Ye'kwana, como também as estratégias nativas contra epidemia e contágio, devem ser levadas em conta quando da tomada de decisões administrativas e planos de contenção do avanço da Covid-19.

A impossibilidade de ingresso em Terras Indígenas durante todo o período de propagação do vírus sugere novas frentes de atuação e estratégias para a realização da pesquisa antropológica. A produção de relatos, dados epidemiológicos em parceria com profissionais de saúde e criação de redes de apoio, são medidas que podem dar visibilidade à difícil situação de enfrentamento da pandemia pelos povos indígenas do Brasil.

\section{Referências Bibliográficas}

ALBERT, Bruce. (1985) Temps du sang, temps des cendres: représentation de la maladie, espace politique et système rituel chez les Yanomami du sud-est (Amazonie brésilienne). Universidade de Paris X-Nanterre. Tese (Doutorado em Etnologia). (1992). "A fumaça do metal: História e representações do contato entre os Yanomami”. Anuário Antropológico n89, Rio de Janeiro: Tempo Brasileiro. (2020). Agora somos todos índios. Folha de São Paulo. Disponível em:

https://www1.folha.uol.com.br/opiniao/2020/04/agora-somos-todos-indios.shtml.

Acesso em: 15 de maio de 2020.

BRASIL, Kátia; COSTA, Emily. (2020). Coronavírus: Povo Yanomami irá questionar na Justiça enterro de jovem sem autorização dos pais, em Roraima. Amazônia Real. Disponível em: https://amazoniareal.com.br/coronavirus-povo-yanomami-iraquestionar-na-justica-enterro-de-jovem-sem-autorizacao-dos-pais-em-roraima/.

Acesso em: 16 de maio de 2020.

FAUSTO, Carlos. (2001). Inimigos fiéis: história, guerra e xamanismo na Amazônia. São Paulo: Edusp.

FONSECA, Antonio Victor et al. (2020). Ameaça e Pressão e Desmatamento em Áreas Protegidas: SAD de novembro de 2019 a janeiro de 2020. Belém: Imazon.

KOPENAWA, Davi; ALBERT, Bruce. (2015). A queda do céu: Palavras de um xamã Yanomami. São Paulo: Companhia das Letras.

RAMOS, Alcida. (1990). Terra e sobrevivência cultural Yanomami. Comissão pela Criação do Parque Yanomami (CCPY), São Paulo. 
(1993). “O papel político das epidemias: o caso Yanomami”. Série Antropologia, 153. Brasília: Departamento de Antropologia/UnB.

RAMOS, Alcida Rita et al. (2020). Nota Técnica para contribuir ao combate da Covid-19 na terra indígena Yanomami. Disponível em: https://5a679a85-ce12-4c6fb23d6c34d69cb631.filesusr.com/ugd/547b78_72a44a188f274ec98fe0e823479da8c2.pdf. Acesso em: 05 de jun. 2020.

Rede de Cooperação Amazônica. (2019a). Protocolo de consulta dos povos Yanomami e Ye'kwana. Boa vista: ISA/ Hutukara Associação Yanomami.

RCA. (2019b). Protocolo de gestão territorial e ambiental Terra Indígena Yanomami com Protocolo de consulta dos povos Yanomami e Ye'kwana. Boa vista: ISA/ Hutukara Associação Yanomami.

RUBIO, Javier Carrera. (2004). The fertility of words: Aspects of language and sociality among Yanomami people of Venezuela. Tese de doutorado em Antropologia Social. Londres: University of St. Andrews.

\section{sobre a autora}

\author{
Marina Sousa \\ É doutoranda em Antropologia Social pela \\ Universidade Estadual de Campinas, onde também \\ obteve o título de mestra em Antropologia. É \\ graduada em Antropologia pela Universidade Federal \\ de Roraima.
}

